\title{
Inventario y registro del Patrimonio de las Corporaciones locales (*)
}

\author{
por \\ ALEJANDRO CUÉLLAR BASSOLS \\ Secretario del Ayuntamiento de Olot (Gerona).
}

Sumario: I. El Inventario DE Bienes de las Entidades locales: 1. El Patrimonio de los entes locales. 2. Elementos constitutivos. 3. El Inventario general de Bienes: A) Notas generales: a) El doble concepto del Inventario. b) Evolución legislativa. c) Naturaleza jurídica del Inventario. B) Contenido del Inventario: a) Su contenido según la sistemática del Reglamento de Bienes. b) Los bienes y derechos revertibles. C) Normas procedimentales: a) Formación. b) Formato del documento. c) Documentos complementarios. d) Inscripciones, clasificación, numeración y datos de los asientos. e) Rectificacion: a') Altas. b') Bajas. $c^{\prime)}$ Alteraciones: $a$ ") Físicas. b") Jurídicas. c") Económicas. f) Anotaciones. g) Comprobacion. h) Aprobaciones. Organo competente. 4. El Inventario de Bienes de las Fundaciones y Establecimientos: A) Personalidad jurídica de estos entes. B) El Inventario de sus bienes. C) Requisitos formales.- $\Pi$. INMATRICULACION DE BIENES DE LAS ENTIDADES LOCALES EN EL RegISTRO DE LA PROPIEDAD: 1. Obligatoriedad. 2. Bienes inscribibles. 3. Títulos inscribibles: A) Normales. B) La certificación del artículo 206 de la Ley Hipotecaria. 4. Dos supuestos «sui generis» de inmatriculacion: A) Reversiones a favor de los entes locales en los casos de incumplimiento de los requisitos del artículo 97 del Reglamento de Bienes. B) Traspaso de la propiedad de edificios escolares estatales a favor de los Ayuntamientos.-III. ConCLusion.

\section{EL INVENTARIO DE BIENES DE LAS ENTIDADES LOCALES}

\section{El Patrimonio de los entes locales.}

Difícilmente puede estudiarse la problemática que ofrece el Inventario de Bienes de las Entidades locales sin tener idea previa

(*) El presente trabajo está basado en la Ponencia redactada por el autor para el III Seminario de la Sección de Estudios de Administración Local de Gerona, celebrado en dicha ciudad el día 28 de septiembre de 1967. 
de todo aquello que integra el patrimonio de las mismas. Nos planteamos, pues, el dualismo que existe entre continente (Inventario) y contenido (Patrimonio).

El Inventario consiste sustancialmente en una determinada relación de bienes, debidamente ordenada y clasificada.

Es obvio que, inicialmente, lo que nos interesa concretar es la diversidad de elementos integrantes de la masa patrimonial de las Entidades locales, ya que el Patrimonio es un concepto mucho más amplio que el de Inventario; y no guardan entre sí absoluta correlación.

\section{Elementos constitutivos.}

El Patrimonio de las Entidades locales está constituido (1) por el conjunto de bienes, derechos y acciones que les pertenecen (2). Avanzando en el examen de esta trilogía patrimonial podemos afirmar que se consideran bienes todas las cosas, entendidas éstas en sentido físico o corporal que son objeto inmediato de las relaciones de señorío (3), que son o pueden ser objeto de apropiación (art. 333 del Código civil). Tales bienes pueden ser muebles o inmuebles.

En cuanto a los derechos, integrarán el Patrimonio municipal aquellos de carácter subjetivo que el ordenamiento jurídico garantizan al ente local (4) bifurcados en la doble vertiente de reales o de obligación.

Podríamos hablar incluso matizando el concepto, de derechos «económicos», es decir, de aquellos que el ordenamiento jurídico

(1) Artículo 182 de la Ley de Régimen local.

(2) De semejante manera la Ley del Patrimonio del Estado de 15 de abril de 1964 lo declara constituido por los bienes que siendo de su propiedad no se hallaren afectos al uso general o a los servicios públicos; los derechos reales y de arrendamiento de que el Estado sea titular, así como aquellos que deriven del dominio de bienes patrimoniales y. los derechos de propiedad incorporal.

Parece más completo el criterio enumerativo de la Ley de Régimen local.

La Ley del Patrimonio del Estado excluye de dicho Patrimonio los bienes de uso y de servicio público en contraposición a lo dispuesto en la legislacín local. Se excluyen asimismo las acciones y los derechos personales, como no deriven del dominio de los bienes patrimoniales.

(3) CASTáN, Derecho civil español, común y foral, Madrid, 1952, tomo I, volumen II, pág. 366.

(4) CAStÁn, ob. cit., tomo I, vol. II, pág. 17. 
habilita para nutrir las Haciendas locales al facultarles para exigir tributos.

Finalmente forman parte también del Patrimonio local las $a c$ ciones, porque aquél no sería efectivo si no gozara de la debida protección jurisdiccional. En definitiva, y según GoNZÁLEZ PÉREZ, la acción no es más que el poder o derecho de promover la actividad jurisdiccional del Estado.

Carácter especial debe atribuirse (dentro del conjunto patrimonial público-local) al llamado patrimonio del suelo regulado por los artículos 72 y siguientes de la Ley de 12 de mayo de 1956. Su carácter finalista, así como la peculiaridad de las normas que lo regulan-sin dejar de constituir bienes inmuebles dentro de la general clasificación apuntada-, le confieren una determinada naturaleza que le sitúa entre los bienes de propios y los de dominio público (5). No debe perderse de vista esta doble naturaleza porque ella puede entrañar dificultades en orden a su Inventario.

\section{El INVENTARio general De Bienes.}

El artículo 200 de la Ley de Régimen local establece la noción terminológica del Inventario al definirlo como «relación valorada de todos los bienes y derechos que pertenecen a una Entidad local».

(5) Sobre la naturaleza de este Patrimonio escribe Miguel Angel NUNEZ RUiz en Derecho urbanistico español, Madrid, 1967: Para BOQUERA OLVER, los bienes que constituyen el patrimonio municipal del suelo son bienes de dominio público. Ahora bien, precisa que lo son con algunas excepciones, puesto que son enajenables mediante desafectación.

A nuestro modo de ver, añade NUNEz RUIZ, la aplicación absoluta del criterio de la afectación, que tiene sus raíces en la antigua publicatio del Derecho romano, tiene el peligro-que ha señalado GarRIDo FaLLA-de la excesiva extensión que el concepto de dominio público puede entonces adquirir, siendo así que es conciliable la existencia de un patrimonio privado de la Administración con la idea de destinación a un fin de interés general.

En nuestra opinión se trata de un «patrimonio separado» dentro del Patrimonio municipal, pero que no tiene más elemento común que la de ser el Municipio un centro unificador o titular de las diversas relaciones o patrimonios.

La doctrina tradicional (Messineo, Vocino, Candian, Wouf) define el patrimonio separado como un complejo de bienes o derechos destinados a un fin particularmente determinado. 
Esta definición peca por exceso porque, como luego veremos, no todos los bienes y derechos que pertenecen a una Entidad local deben ser inventariados. De otra parte elimina de una manera expresa las acciones, toda vez que las excluye del contenido del Inventario, quizá porque las considera como poder o facultad inherente a los propios bienes y derechos ya inventariados.

\section{A) Notas generales.}

a) El doble concepto del Inventario.

El Inventario-y esto en la práctica es importante-puede concebirse desde dos puntos de vista distintos: uno orgánico, formativo o constitutivo, y otro contable en cuanto el importe de sus bienes y derechos se refleja en la situación económico-financiera de la Entidad.

En el presente estudio omitimos el segundo punto de vista.

b) Evolución legislativa.

Someramente puede fijarse en estos tres hitos o mojones legislativos:

Hasta la aparición del Estatuto municipal de 1924 el Inventario de Bienes no tiene alcance alguno, ni siquiera contable. Es curioso observar que cuando más importancia tuvieron los patrimonios municipales (antes de las leyes desamortizadoras y aun después) más descuidada fuera la protección documental de los mismos.

El Reglamento de Haciendas locales de 1924 encomienda, por primera vez, a la Comisión permanente la formación del Inventario general del Patrimonio municipal y atribuye su aprobación al Ayuntamiento pleno.

La Ley municipal de 1935 dedicaba ya, con mayor atención, los artículos 148 y 149 al Inventario de Bienes.

Estos fueron los dos antecedentes legales a los preceptos de la Ley de Régimen local y Reglamento de Bienes, aunque su eficacia práctica fuese virtualmente nula. 
c) Naturaleza juridica del Inventario.

¿Es el Inventario un registro jurídico patrimonial? ¿Reconoce y garantiza el derecho? (6).

A nuestro juicio, el Inventario es tan sólo un registro administrativo cualificado. Un simple recordatorio o «para memoria» (7), pues sus asientos no hacen prueba frente a terceros, ni declaran el derecho, ni mucho menos lo hacen nácer (lo constituyen) (8).

En nuestros textos legales el Inventario se configura como un documento que recuerda-un simple recordatorio-, y tanto es así que, en apoyo de nuestra opinión, resulta altamente significativa-casi delatora-la expresión «de modo que sirva de recordatorio constante» que se desliza en el texto del artículo 27 del Reglamento de Bienes.

\section{B) Contenido del Inventario.}

El Inventario debe referirse, por lo tanto, a los bienes y derechos de las Entidades locales. Pero no a todos, a pesar de la tajante declaración del citado artículo 200 de la Ley de Régimen local, porque al desarrollarse este precepto en el artículo $16 \mathrm{del}$ Reglamento de Bienes se declara que las Corporaciones locales estarán obligadas a formar inventario que comprenda los bienes patrimoniales pertenecientes a la respectiva Entidad y los de dominio público que fueren edificios o tuvieren carácter mueble. Aquí el contenido del Inventario se constriñe notablemente. Descarta en primer lugar los derechos, si bien los menciona la Ley y los artículos siguientes del mismo Reglamento, y prescinde de la clasificación en «de uso» $y$ «de servicio» de los bienes

(6) Sobre esta cuestión doctrinal véase Moreno PÁEZ en REviSTA DE Estudios DE LA VIDA LOCAL, 1957, núm. 95, pág. 577.

(7) Elementos de Contabilidad administrativa, Barcelona, 1951, pág. 138, y artículo 27 del Reglamento de Bienes.

(8) En orden a su mayor o menor eficacia jurídica los libros registro han cubierto históricamente las siguientes etapas: $1 .^{3}$ Los libros recuerdan. 2." Los libros prueban. $3 .^{\circ}$ Los libros declaran el derecho ya nacido, y. 4.? Los libros constituyen el derecho. El Inventario de Bienes de las Entidades locales, tal como está concebido en los textos legales actuales, no ha traspuesto todavia la primera etapa. 
de dominio público, introduciendo, en cambio, los conceptos «edificios» $y$ «muebles» que, según veremos, inducen a confusión.

A tenor del artículo 16 del Reglamento de Bienes, los únicos bienes inventariables serían los siguientes:

Bienes. $\begin{cases}\text { De dominio público. } & \begin{cases}\text { De uso ...... } & \text { Ninguno. } \\ \text { De servicio .. } & \text { Solamente los edificios y } \\ \text { muebles. }\end{cases} \\ \text { Patrimoniales } \ldots . . . . . . & \left\{\begin{array}{l}\text { De propios ... } \\ \text { Comunales ... }\end{array}\right\} \text { Todos. }\end{cases}$

Por regla general, y a tenor de esta clasificación, deberán omitirse los bienes de uso público (parte integrante del dominio público) porque no se concibe un edificio ni un bien mueble destinado al dicho uso (véase, al respecto, la enumeración del artículo 3.o del Reglamento de Bienes). Por excepción, se inventariarán las edificaciones a que se refiere el número 2 del citado artículo 3.․, en el único y circunstancial supuesto que contempla: mientras «no estuvieren demolidas y continuaren ocupadas por los antiguos dueños, arrendatarios o precaristas, si las mismas construcciones o las superficies sobre que se levantaron hubieren de quedar destinadas a alguno de los usos a que se refiere el párrafo anterior». Si tales edificaciones no quedan afectas a estos usos pierden su naturaleza de bienes de uso público y pasan a bienes de servicio público o patrimoniales cuyo inventario es preceptivo.

Mayores dificultades ofrece el inventario de los bienes de servicio público si seguimos la casuística del artículo 4. del Reglamento de Bienes.

¿Es que utilizando la directriz del artículo 16 del Reglamento de Bienes sólo deben inventariarse los edificios destinados a servicios públicos y aquellos bienes de igual destino que tuvieren carácter mueble?

¿Qué alcance debe darse a la palabra edificio?

Examínese la enumeración del citado artículo $4 .^{\circ}$ y contéstese sin ambiguiedades, hasta qué punto pueden considerarse edifig los montes catalogados de propiedad provincial, los monume 
los campos de deportes, las piscinas e incluso determinados frontones.

Si ello fuera así, de la extraordinaria variedad e importancia del dominio público-en su especialidad de servicio-deberiamos eliminar del Inventario numerosos bienes que los más elementales principios de seguridad y buena administración aconsejan su tutela documental $y$, en consecuencia, su inventario.

Así, y por vía de ejemplo, ofrece duda a la luz del citado artículo 16, el inventario de muchos bienes de servicio tales como redes de agua, de alcantarillado y de alumbrado eléctrico, las señales de tráfico, solares o terrenos destinados a la prestación de servicio público, los cementerios, etc. etc., y de los cuales no puede predicarse que sean bienes muebles $\mathrm{y}$, mucho menos, edificios. En tal caso y ciñéndonos a la letra del artículo 16 todos ellos deberían excluirse del Inventario, lo que no parece acertado en aras, por lo menos, de una mayor garantía o tutela y de los. efectos contables que su inclusión pueden motivar.

A nuestro juicio, el contenido del Inventario, y su traducción al precepto legal correspondiente, debería ser éste:

a) Bienes de dominio público. $\left\{\begin{array}{c}\text { Edificios a que se refiere el número } 2 \text { deI } \\ \text { artículo } 30^{\circ} \text { del vigente Reglamento de } \\ \text { Bienes. } \\ \text { Todos los destinados a la prestación de } \\ \text { servicios públicos. }\end{array}\right.$

b) Bienes patrimoniales ...... $\left\{\begin{array}{l}\text { Comunales. } \\ \text { De propios. }\end{array}\right.$

c) Derechos (dimanantes no de un precepto legal, sino de justo título).

a) Su contenido según la sistemática del Reglamento de Bienes.

A tenor de lo prevenido en el artículo 17 del Reglamento de Bienes podemos formular el siguiente cuadro sistemático de los bienes y derechos inventariables: 


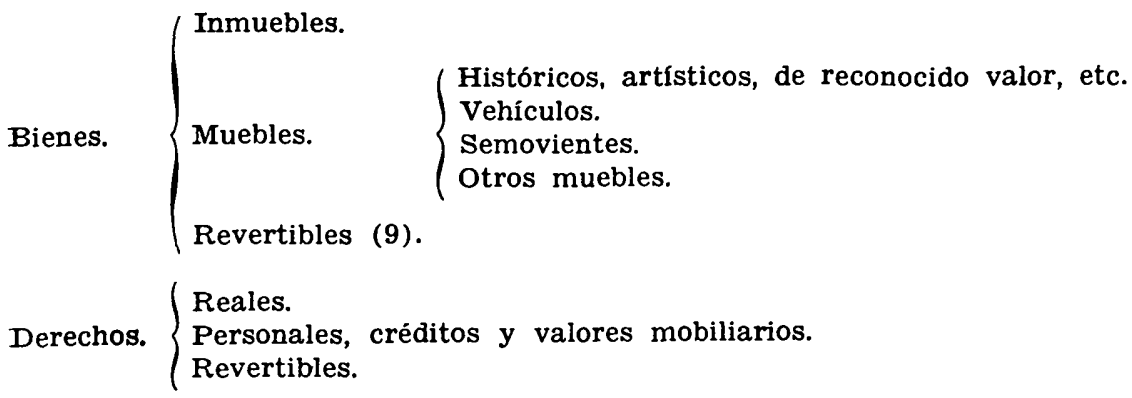

Como puede observarse, el Reglamento de Bienes no establece agrupación alguna de bienes por razón de su destino o afección. La clasificación-completa en todos sus extremos-se aparta del difuso e inconcreto criterio expuesto en el $\tan$ mencionado artículo 16.

Respecto del inventario de los bienes, como regla general deberán relacionarse todos los de servicio público $\mathrm{y}$, excediéndonos de los estrechos límites del artículo 16 del Reglamento de Bienes, aconsejaríamos que se inventariaran todos, aunque no tuvieran el carácter o la consideración de edificaciones. Por el contrario, los bienes de uso público, con la sola excepción de los edificios a que alude el número 2 del artículo 3. del Reglamento de Bienes, no deberán inventariarse nunca.

Mayores dificultades ofrece el inventario de los derechos, que constituye el segundo grupo integrante del Patrimonio municipal. Debe tenerse muy en cuenta que los derechos se dividen en dos grupos bien distintos: los reales y los personales.

Los derechos reales, por recaer directamente sobre cosas determinadas del mundo exterior pueden ser objeto de disfrute por todos y cada uno de los habitantes del Municipio. En su consecuencia, pueden tener naturaleza patrimonial (10) o de dominio

(9) Puede sorprender doctrinalmente esta clasificación, basada en el articulo 17 del Reglamento de Bienes, por situar a los bienes revertibles en el mismo nivel de clasificación que los bienes inmuebles y muebles.

El motivo es, quizá fundamentalmente, su interés práctico y de pura memoria, de bienes que salieron del Inventario a plazo, o con una condición resolutoria o que aunque permanecen en el mismo, la Corporación ha cedido su posesión, por concesión o arrendamiento según se detalla en el punto b) siguiente.

(10) Por ejemplo, el derecho de vistas cuyo predio dominante sea un bien inmueble de propios. 
público. En la esfera administrativa juega, en este caso, un importante papel la idea finalista del Derecho. Un derecho patrimonial puede afectar a la esfera privada de la Administración (la actuación privada que tantas cuestiones doctrinales promueve) o bien al dominio público-uso o servicio-, entendiendo por tal el conjunto de cosas directa e inmediatamente destinadas a las funciones administrativas propias o privativas de los entes locales (11).

De este último carácter serían las servidumbres administrativas a favor del dominio público (12).

Teóricamente la legislación adopta, en cuanto a la enumeración o existencia de derechos reales, la cláusula del numerus apertus, a tenor de la cual son posibles tantos derechos reales como poderes puede ejercer el hombre sobre las cosas.

Entre ellos destacan los derechos reales de servidumbre (13), sobre los cuales abunda la literatura jurídica (14).

En orden al Inventario-por su carácter tutelar del Patrimonio municipal y de perenne recordatorio viable a través de sus asientos-y por lo que respecta a los derechos reales, creemos que sólo deben tener acceso al documento que estudiamos, aquellos cuyo nacimiento se debe no a la Ley, sino a la voluntad de las partes mediante título adecuado. Igual criterio cabe mantener en cuanto a los derechos de obligación, los cuales por su misma naturaleza tendrán siempre la consideración de patrimoniales, es decir, pertenecerán a la Entidad local en régimen de Derecho pri-

(11) M. BALlBE, Concepto del dominio priblico, Bosch, Barcelona.

(12) GaRrido FALLA, Tratado de Derecho administrativo, vol. II, pág. 415.

(13) Servidumbres de uso público, verbigracia, la definida en el artículo 553 del Código civil; servidumbres de servicio público, como la de acueducto para el abastecimiento de agua a una población, y las servidumbres de carácter patrimonial, como la de luz y vistas constituida a favor de un edificio municipal de propios.

(14) Aparte de los tratados de carácter general, a título de ejemplo citamos: Ramón MARTín MATEO, «La propiedad monumental» y «El Estatuto de la propiedad inmobiliaria», en Revista de Administración Pública, número 49, enero-abril 1966, págs. 76, 84 y 85, y núm. 52, enero-abril 1967, página 133, respectivamente; Francisco LuCAS FERNÁNDEZ, «Naturaleza, fines y principios generales de legislación urbanística...», en Revista de Derecho Urbanistico, mayo-junio 1967, pág. 40; sentencia del Tribunal Supremo de 3 de noviembre de 1967 (Aranzadi 4.042); Alberto VERA, «Las servidumbres y otros derechos reales...», en REVISTA DE ESTUdios DE LA VIDA LOCAL, mayojunio 1967, pág. 400. 
vado, por ser imposible su disfrute o pertenencia al común de los vecinos como de uso o servicio público.

Deberán inventariarse como derechos personales las obligaciones consistentes en dar, hacer o no hacer, de las cuales la Corporación respectiva sea acreedora y cuya relación jurídica se rija por las normas de Derecho privado. Se excluyen así los derechos que hemos calificado económicos (exacciones propiamente tales, dimanantes del poder de imperio de la Administración).

\section{b) Los bienes y derechos revertibles.}

Mucho podría escribirse sobre la importancia de la inscripción en el Inventario de los bienes y derechos de carácter revertible, a favor de la Corporación, precisamente por la nota de «para memoria» que le hemos atribuido. Constituye, su inclusión en el documento, una medida de defensa precautoria, garantía de la integridad del Patrimonio local.

Hay que velar siempre para que los bienes y derechos cedidos vuelvan al concluir el plazo impuesto o al cumplirse las condiciones estipuladas, al respectivo Patrimonio del que, un día, fueron desgajados.

Son bienes y derechos revertibles (art. 27 del Reglamento de Bienes) aquellos cuyo dominio o disfrute hubiere de revertir o consolidarse a favor de la Entidad en alguno de estos dos supuestos:

1.- Llegado cierto día, o sea al cumplirse determinado plazo.

2. Al cumplirse o no determinada condición.

Deben, por lo tanto, inventariarse en el epígrafe 8.ํ, entre otros, los bienes y derechos siguientes:

a) Los cedidos bajo condición o plazo.

b) Las concesiones (demaniales o de servicios).

c) Los arrendamientos sobre bienes de las Entidades locales.

Un supuesto al que debemos dedicar nuestra atención es aquel -que se da frecuentemente en la práctica-referente a la cesión de bienes que de su acervo patrimonial suelen efectuar las Entidades locales a favor de personas o entidades diversas, bien sea a título gratuito, bien sea a título oneroso. 
Téngase muy en cuenta que, por estricta aplicación de lo dispuesto en el artículo 97 del Reglamento de Bienes, todas las cesiones de bienes patrimoniales quedarán sujetas (la locución es imperativa) a las dos condiciones siguientes:

1. ${ }^{a}$ Que los fines para los cuales se hubiesen otorgado se cumplan en el plazo máximo de cinco años, y

2. ${ }^{a} \quad$ Que su destino se mantenga durante los treinta años siguientes.

Prevalece aquí el carácter finalista de las cesiones en virtud del principio del interés público que informa toda la actividad de los entes locales. Transcurrido uno $u$ otro plazo sin que se hubieren cumplido las citadas condiciones, los bienes-añade el citado artículo 27-revertirán automáticamente de pleno derecho al $\mathrm{Pa}$ trimonio de ia Entidad cedente con sus pertenencias y accesiones. Los términos del precepto son tajantes y contundentes. No admiten réplica.

Sin embargo, debemos profundizar un poco más la cuestión y analizar cuál sea el alcance del término automáticamente en el sentido de si se requiere o no el cumplimiento de algún trámite o requisito formal para el perfeccionamiento de la reversión.

Entendemos (15) que la voz automáticamente no autoriza a formalizar la reversión sin más trámite. Automáticamente no puede ser sinónimo de «sin formalidad alguna».

En esta cuestión conviene distinguir dos aspectos distintos y que pueden inducir a confusión: la inscripción en el Inventario y la inmatriculación en el Registro de la Propiedad.

Nada obsta, a nuestro juicio, para que en el Inventario se refleje la caducidad de cualquiera de las dos anteriores condiciones: cumplimiento de los fines en el término de cinco años y mantenimiento del destino durante los treinta siguientes. Insistimos en que el Inventario no tiene más eficacia que la de cualquier simple recordatorio. Los asientos que en tal sentido se practiquen, tienen perfecta virtualidad. Bastará que el Ayuntamiento, como resultado de un expediente sumario que tienda a la prueba

(15) Seguimos a Altarriba en su intervención en el «Seminario de la Sección de Estudios de Gerona». 
de los hechos, así lo acuerde. Del problema registral nos ocuparemos en su lugar.

\section{C) Normas procedimentales.}

\section{a) Formación.}

La formación de los Inventarios corresponde a los Secretarios de Ayuntamiento como una de tantas obligaciones que les impone el artículo 145 del Reglamento de Funcionarios de Administración local en cuanto a tenor de su número 6, les corresponde «gestionar y dirigir los actos encaminados a la inmatriculación, compra, enajenación e inventario de los bienes que constituyan o hayan de constituir el Patrimonio de la Entidad...».

Los Inventarios serán autorizados también por dicho funcionario, con el visto bueno del Presidente de la Corporación.

Obsérvese, porque es importante, que la formación del Inventario no está sujeta a tramitación alguna y que no exige, en ningún momento, el requisito de publicidad o de información pública $\tan$ frecuente en otros registros administrativos.

\section{b) Formato del documento.}

El documento es el soporte material del Inventario. Ninguna disposición reglamentaria indica cuáles deben ser las características del documento, en sí mismo, como tal documento.

A la hora de escoger el más adecuado nos inclinamos por aquel que, dotado de las mayores garantías de autenticidad, tenga reconocidas ventajas prácticas. Aquí los nuevos sistemas de mecanización y modernos sistemas técnicos tienen indudablemente un amplio campo de acción (lo mismo podría afirmarse con referencia a los actuales libros de Actas).

\section{c) Documentos complementarios.}

Es preceptivo que, siempre que fuere posible, se levanten planos de alzado y planta de los edificios y parcelarios que determinen la situación, linderos y superficies de los solares, parcelas no edificadas y de las fincas rústicas. 
De los bienes muebles, históricos, artísticos o de considerable valor económico, se obtendrán fotografías debidamente autenticadas.

Todos los documentos que refrendaren el Inventario y en especial los títulos de dominio, actas de deslinde y valoración, planos y fotografías se archivarán con separación de la demás documentación municipal.

d) Inscripciones, clasificación, numeración y datos de los asientos.

El Reglamento de Bienes, en sus artículos $17 \mathrm{y}$ siguientes, detalla minuciosamente estos extremos, haciendo innecesario insistir sobre ellos.

Sólo conviene aclarar el extremo i) del artículo 19 que se refiere al título en virtud del cual se atribuyen los bienes inmuebles a la respetiva Entidad. Téngase en cuenta que el Código civil emplea la palabra título en el sentido de instrumento o documento (artículos 385, 386, 387, 1.065, 1.066) y. en el de causa o razón jurídica de la adquisición de un derecho.

Este dato debe comprender, a nuestro juicio, las dos acepciones de la palabra. Así, pues, se hará constar la razón o modo de la adquisición anotando por ejemplo: compraventa, permuta, usucapión, donación, herencia, etc., en cuyo caso se especificará el título escrito acreditativo de la adquisición, añadiendo «mediante escritura pública otorgada el día... ante el Notario don...».

En determinados casos el modo de adquisición será el de «posesión desde tiempo inmemorial». Si se careciera de título escrito deberá hacerse constar así.

\section{e) Rectificación.}

La rectificación del Inventario debe verificarse anualmente y en ella se reflejarán las vicisitudes de toda índole de los bienes y derechos, ocurridas durante el año anterior.

No se fija en el Reglamento de Bienes la fecha a la que debe referirse la rectificación, si bien lo lógico y normal es que sea la del 31 de diciembre de cada año, por su correspondencia con los libros de contabilidad y fechas de los balances e inventarios. 
Las vicisitudes que pueden afectar a los bienes y derechos son las siguientes:

1. Altas.

2. Bajas.

3. Alteraciones. $\left\{\begin{array}{l}\text { Físicas. } \\ \text { Jurídicas. } \\ \text { Económicas. }\end{array}\right.$

Un ejemplar de la rectificación deberá remitirse al Gobierno Civil tal como dispone el artículo 31.1 del Reglamento de Bienes.

$\left.a^{\prime}\right)$ Altas.

Responden, como es lógico, a toda clase de adquisiciones. Como caso sui generis exponemos el que contempla el artículo 23 del Decreto-ley de 2 de julio de 1964 (B.O. E. del 6) cuyo tenor literal es como sigue: «Todos los edificios escolares y viviendas: para maestros existentes en el término municipal en donde radiquen las Escuelas nacionales de Enseñanza Primaria serán de propiedad municipal, si bien no se podrán dedicar a fines distintos a la enseñanza, sin previa autorización del Ministerio de Educación Nacional».

¿Qué alcance tiene este precepto? Su contenido podría aceptarse como una simple declaración programática sin eficacia inmediata hasta tanto fuese desarrollado por otras disposiciones de carácter ejecutivo. Pero no es así. Nos consta que la ejecutividad de la disposición es absoluta. A partir de la fecha de este Decreto-ley la propiedad de los edificios escolares ha sido transmitida a los Ayuntamientos.

Ahora bien, la inscripción de tales inmuebles en el Inventario nos parece incuestionable, dada su especial naturaleza de registro administrativo, sin mayores consecuencias. Otra cuestión será la de su inmatriculación en el Registro de la Propiedad de la cual nos ocuparemos en su lugar adecuado.

b') Bajas.

Corresponderán a ventas, cesiones, permutas, destrucción y desaparición total o parcial de los bienes, etc.

c) Alteraciones.

$a^{\prime \prime}$ Físicas. Se producirán por derribos, reformas, aumentos 
o disminución del volumen edificado, segregaciones, agrupaciones, cambios operados en los bienes, etc.

b") Jurídicas. Se refieren a los cambios de calificación jurídica de los bienes previstos en el artículo 8. ${ }^{\circ}$ del Reglamento de Bienes.

La alteración de la expresada calificación puede tener lugar: $a^{\prime \prime \prime) ~ p o r ~ s i m p l e ~ t r a n s c u r s o ~ d e l ~ t i e m p o ~ y ~} b^{\prime \prime \prime)}$ por acto voluntario y formal de la Corporación.

$a^{\prime \prime \prime)}$ Por simple transcurso del tiempo.

1) Afectación de bienes a un uso o servicio público comunal.

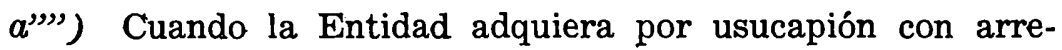
glo a Derecho civil el dominio de una cosa que viniere estando destinada a un uso o servicio público o comunal.

$b^{\prime \prime \prime)) ~ C u a n d o ~ d u r a n t e ~ v e i n t i c i n c o ~ a n ̃ o s ~ s e ~ u t i l i z a r e n ~ b i e n e s ~}$ de propios en uso o servicio público o comunal, o siendo bienes comunales, durante el mismo período de tiempo fueren objeto de uso o servicio públicos.

2) Desafectación de los bienes de uso y de servicio público y de los comunales. Se opera por el mero transcurso de veinticinco años y se convierten en bienes de propios si efectivamente han dejado de utilizarse con aquellos caracteres.

b"') Por acto formal de la Corporación.

La alteración, en este caso, tiene lugar mediante expediente, en el que se demuestra la conveniencia del cambio de afectación, total o parcial, al uso, servicio o aprovechamiento de que se trate.

El expediente deberá ser resuelto, previa información pública durante un mes, por la Corporación local respectiva, mediante acuerdo adoptado con el quorum que señala el artículo 303 de la Ley.

c) Económicas. Deben practicarse quinquenalmente y a efectos contables conforme determina la Regla 63 de la Instrucción de Contabilidad.

De todos modos, la trascendencia de estas valoraciones es muy relativa, ya que no se tienen en cuenta en casos tan importantes como podían ser a título de ejemplo: para la liquidación del «Impuesto sobre bienes de las personas jurídicas», en cuyo caso debe estarse a lo determinado en el artículo 138 en relación con 
el 150 de la Ley de Reforma tributaria de 11 de junio de 1964; y para las enajenaciones y permutas de bienes, puesto que para su justiprecio deben cumplirse los dictados del artículo 103 del Reglamento de Bienes.

De cuanto queda dicho se deduce la escasa importancia de estas retasaciones e incluso de las valoraciones iniciales reseñadas en los asientos del Inventario.

Seguimos, pues, a Pedro LuUch (16) cuando afirma que, para el Inventario, «la fijación de la valoración de los elementos patrimoniales que lo constituyen no tiene trascendencia alguna». Ello nos confirma una vez más el carácter memorístico del mismo.

\section{f) Anotaciones.}

Las variaciones deben hacerse constar en los espacios en blanco que el artículo 18.2 del Reglamento de Bienes dispone se dejen a continuación de cada asiento.

\section{g) Comprobación.}

Establece el Reglamento de Bienes la obligación de efectuarse comprobaciones del Inventario siempre que se renueve la Corporación, advirtiendo que el resultado se consignará al final del documento, sin perjuicio de levantar acta adicional con objeto de deslindar las responsabilidades que puedan derivarse para los miembros salientes y, en su día, para los entrantes.

Este trámite, que en la práctica suele omitirse, tiene una importancia extraordinaria. Constituye un acto de tutela y defensa de los patrimonios municipales que, de haberse previsto y cumplido, hubiera evitado abusos y negligencias inexcusables.

\section{h) Aprobaciones. Organo competente.}

El órgano competente tanto para la aprobación del Inventario inicial como para la de sus rectificaciones y comprobaciones ulteriores, es el Ayuntamiento pleno o la Diputación provincial.

(16) Pedro LluCh CAPDEvila, Elementos de Contabilidad administrativa, Barcelona, 1951, pág. 137. 


\section{El Inventario de Bienes de las Fundaciones}

Y ESTABLECIMIENTOS.

\section{A) Personalidad jurídica de estos entes.}

El Reglamento de Bienes se ocupa de los Inventarios pertenecientes a Fundaciones y Establecimientos, con personalidad propia e independiente, cuando su legítima representación o patronato correspondiere a las Corporaciones locales.

Nos hallamos ante el supuesto que contemplan los artículos 85 a 88 del Reglamento de Servicios, es decir, el caso de la Fundación pública del Servicio.

Estas Fundaciones deben su creación $u$ origen, bien a un acuerdo corporativo (por aconsejarlo así el adecuado desarrollo de las funciones de beneficencia, cultura o de naturaleza económica), bien a una disposición legal, bien a la voluntad de su fundador mediante la adquisición por parte de los Ayuntamientos de determinados bienes particulares, adscritos por aquéllos a un fin.

Los términos Fundaciones y Establecimientos excluyen-a nuestro juicio-cualquier otro ente municipal con personalidad jurídica propia, tales, por ejemplo, las Sociedades mercantiles creadas al amparo de los preceptos del Reglamento de Servicios que las regulan.

Los bienes de estas Sociedades no deben, pues, inscribirse en el Inventario general del Ayuntamiento ni en los que contemplamos en el presente epígrafe y a que se refiere el artículo $30 \mathrm{del}$ Reglamento de Bienes.

\section{B) El Inventario de sus bienes.}

Estas Fundaciones poseen patrimonio especial afecto a los fines específicos de la institución. Este patrimonio y la dotación de personalidad son las notas características de esta figura jurídica.

El hecho de que posean patrimonio independiente (al disolverse la institución la Corporación le sucede universalmente) justifica para sus bienes la exigencia de un Inventario separado. 
C) Requisitos formales.

Estos Inventarios se forman con idénticos requisitos al general del Ayuntamiento, con la única peculiaridad de que antes de la firma del Secretario deberá figurar la del Director o Administrador del correspondiente Establecimiento y de que un ejemplar queda en el respectivo Establecimiento, otro en las oficinas centrales de la Corporación y otro en el Gobierno Civil.

\section{INMATRICULACION DE BIENES DE LAS ENTIDADES LOCALES EN EL REGISTRO DE LA PROPIEDAD}

\section{OBLigatoriedad.}

Para mayor seguridad de los patrimonios municipales y provinciales la Ley impone a las Corporaciones locales el deber de inscribir sus bienes inmuebles y derechos reales en el Registro de la Propiedad. Lo que para los particulares puede ser potestativo constituye exigencia legal para las Entidades locales.

En España (frente a otros sistemas: alemán, suizo, etc.), las inscripciones son declarativas, es decir, el derecho nace del título, antes de la inscripción, la cual se limita solamente a declarar a los terceros que el derecho ha nacido. Como únicas excepciones a este principio de carácter general se hallan entre otras la inscripción de la hipoteca y el derecho real de superficie concedido por Entidades públicas (art. 158 de la Ley del Suelo), en cuyos casos la inscripción es constitutiva, ya que por su virtud nace el derecho.

El Registro de la Propiedad es público para los que tengan interés conocido en averiguar el estado de los bienes y derechos reales (arts. 605, 606 y 607 del Código civil).

\section{BIENES INSCRIBIBLES.}

Lo son obligatoriamente todos los bienes inmuebles de servicio público enumerados en el artículo 4. del Reglamento de Bie- 
nes y todos los bienes patrimoniales (también inmuebles), sean de propios o comunales (17).

La única excepción se concreta a las ermitas, capillas o templos que pertenezcan de pleno derecho al Ayuntamiento, puesto que no son inscribibles, por declaración expresa del artículo 5.4 del Reglamento Hipotecario, siempre que estén abiertas al culto, pues tal precepto establece que quedan exceptuados de la inscripción los templos destinados al culto católico.

Se excluyen, pues, de la inmatriculación, según se desprende de lo dicho, los bienes de uso público.

En resumen, y como criterio práctico, deben obligatoriamente inscribirse en el Registro de la Propiedad:

a) Todos los bienes inmuebles de servicio público.

b) Todos los bienes inmuebles de propios y los comunales que: pertenezcan a la comunidad de vecinos, y

c) Los derechos reales, a excepción hecha de las servidumbres legales, en tanto en cuanto pueden recaer o referirse a los inmuebles citados en los dos epígrafes $a$ ) y $b$ ) anteriores.

\section{TÍtulOS INSCRIBIBLES.}

Tomamos aquí la palabra título como sinónima de documento o instrumento originario que acredita fehacientemente la pertenencia de un derecho a favor de una Corporación local.

Nos interesa, pues, conocer los títulos que tienen acceso al Registro de la Propiedad y que pueden motivar en él la inmatriculación de bienes y derechos pertenecientes a las Entidades. locales.

\section{A) Normales.}

Si nos atenemos a lo dispuesto en el artículo 199 de la Ley

(17) Se ha suscitado una cuestión interesante a la vista de la actual legislación hipotecaria, sobre si han de entenderse exceptuados de inscripción sólo los bienes de uso público definidos en el artículo 184 de la Ley de Régimen local o por el contrario todos los de dominio público (uso y servicio). Sobre este problema veánse las autorizadas opiniones de GonZález Pérez y Roca Sastré en Revista de Estudios de la Vida Local, 1962, páginas 191 y siguientes. 
Hipotecaria los medios de inmatriculación en el Registro de la Propiedad de bienes y derechos son tres, a saber:

a) Expediente de dominio.

b) Título público de adquisición.

c) Certificación del artículo 206 de la Ley Hipotecaria.

Pero el artículo 299 de su Reglamento añade que «también podrán inscribirse sin el requisito de la previa inscripción los títulos, cualquiera que sea su fecha, que fueren inscribibles directamente con arreglo a leyes y disposiciones especiales» (18).

Con arreglo a estas disposiciones especiales, y por lo que a la actividad municipal respecta, a los títulos de inmatriculación anteriores, nosotros añadiríamos, sin ánimo de agotar la materia, los siguientes:

a) Actas de ocupación de inmuebles por expropiación forzosa, acompañadas del resguardo del depósito de la indemnización legal (art. 154 de la Ley de Régimen local).

b) Acuerdo de reparcelación con referencia al resto de la finca agrupada que se inscribe a favor del Ayuntamiento (Reglamento de Reparcelación de 7 de abril de 1966).

c) Actas de ocupación acompañadas del resguardo del depósito de la indemnización legal, con los actos administrativos de constitución, modificación o extinción forzosa de servidumbres privadas o administrativas sobre dominio privado (art. 55.3 de la Ley del Suelo).

d) Acta de ocupación y pago de inmuebles de edificación forzosa adquiridos por el Ayuntamiento si no se formaliza en escritura notarial (art. 29 del Reglamento de 5 de marzo de 1964).

e) Testimonio del acuerdo en virtud del cual se verifiquen las operaciones de agrupación, división y segregación de fincas del Ayuntamiento (por analogía a lo dispuesto en el art. 43.2 de la Ley del Patrimonio del Estado de 15 de abril de 1964 y artículo 86 de su Reglamento) (19).

(18) RoCA SASTRE al estudiar esta materia afirma que, a la luz del actual Reglamento, son diez los medios, procedimientos o títulos de inmatriculación. Véase su enumeración en Derecho hipotecario, Bosch, Barcelona, 1948, tomo II, pág. 436.

(19) Sobre la aplicación analógica de estos dos últimos preceptos, transcribimos el criterio sustentado por Altarriba en el «Seminario de la Sec- 
f) Supuesto genérico previsto en el artículo 209 de la Ley del Suelo.

B) La certificación del artículo 206 de la Ley Hipotecaria.

Entre los medios de inmatriculación de inmuebles en el Registro de la Propiedad, debemos hacer especial mención de la certificación a que se contrae el artículo 206 de la Ley Hipotecaria.

Cuando la Ley de Régimen local en su artículo 199 impone a los Ayuntamientos la obligación de inscribir sus bienes inmuebles y derechos reales, arbitra el procedimiento para llevar a cabo la inmatriculación añadiendo que será suficiente, a tal efecto, «certificación que, con relación al Inventario aprobado por la respectiva Corporación, expida el Secretario, con el visto bueno del Alcalde, certificación que producirá iguales efectos que una escritura pública».

Este procedimiento sólo puede entrar en juego en el único caso que la finca no esté inscrita en el Registro de la Propiedad y no posea la Corporación local título idóneo de la adquisición.

Estas certificaciones de dominio obedecen, según argumenta. Roca SASTRE (20) al deseo del legislador de evitar que el Estado y entes públicos tuvieren que acudir al expediente de dominio como cualquier particular. Precisamente porque se trata de certificaciones de dominio, no proceden ni son permitidas para la inscripción de derechos reales.

Por lo tanto, para que estas certificaciones operen sus peculiares efectos es necesario que los bienes pertenezcan en pleno dominio a las Corporaciones locales, que éstas carezcan de título de dominio escrito inscribible y que las fincas no se hallen inmatriculadas.

Es evidente que cuando la Ley Hipotecaria se refiere al título

ción de Estudios de Gerona»: 1.० Porque los fundamentos son iguales. 2. Porque no se produce cambio de titularidad. 3.9 Porque la Ley Hipotecaria trata juntos los bienes del Estado y los de los Municipios. 4. ${ }^{\circ}$ Porque en los casos de agrupación, división y segregación no existe negocio jurídico alguno, y 5.: Porque el Registro de la Propiedad tiene por objeto proteger al tercero, y al tercero interesado no puede importarle la descripción de la finca.

(20) Derecho hipotecario, obra citada en la nota 18, pág. 442. 
escrito está empleando la voz título como sinónimo de documento. En cambio, cuando dice que la certificación expresará el título de adquisición se refiere a la razón jurídica de la adquisición del dominio en el sentido complejo de circunstancias que determinan aquella adquisición. En este caso deberá hacerse constar, bien la posesión inmemorial, bien la construcción de la finca por el Ayuntamiento o cualquier otra circunstancia acreditativa de la pertenencia o atribución de la finca a la Entidad.

En la práctica (21) se admite también la utilización, por parte de las Entidades locales, del procedimiento del artículo 206 de la Ley Hipotecaria, en aquellos casos en que el título otorgado a favor de las mismas, aun siendo inscribible, no lo es inmediatamente y ello al objeto de no perjudicar los públicos intereses que, en determinados casos, pueden precisar una rápida inmatriculación. Tal por ejemplo, el caso de una compra en la que el vendedor no posee título escrito y que-sin embargo-la escritura pública de la misma es inscribible con arreglo al procedimiento del artículo 205 de la mencionada Ley, cuando transcurra un año a partir de la fecha de su otorgamiento.

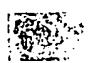

4. DoS SUPUESTOS «SUI GENERIS» DE INMATRICULACIÓN.

A) Reversiones a favor de los entes locales en los casos de incumplimiento de los requisitos del artículo 97 del Reglamento de Bienes.

Establece el artículo 97 del Reglamento de Bienes que cuando no se cumplan en el plazo de cinco años los fines que motivaron la cesión de bienes a terceros, o bien cuando el destino de los mismos no se mantenga durante los treinta años siguientes a la cesión, los bienes revertirán automáticamente, de pleno derecho, al patrimonio de la Entidad cedente con sus pertenencias y acciones.

Es evidente que la voz automáticamente no puede interpretarse en el sentido de que pueda la reversión tener acceso, sin

(21) Recogemos la opinión del Registrador señor ALtaRriba expuesta en el citado «Seminario de Estudios». 
formalidad alguna, en el Registro de la Propiedad. Siempre será indispensable-puesto que los bienes en todos los casos estarán debidamente registrados_-disponer de título bastante para formalizar la inscripción de tal reversión.

El trámite, en el caso que contemplamos, sería, pues, el siguiente: un requerimiento notarial del Ayuntamiento al cesionario invitándole, como consecuencia del incumplimiento de cuanto previene el citado precepto, a ceder nuevamente el inmueble al Ayuntamiento «con sus pertenencias y accesiones», y en el caso de acceder a la invitación otorgar la pertinente escritura pública de reversión. En el caso de que el cesionario o sus causahabientes se negaren, el Ayuntamiento debería solicitar la reversión en juicio ordinario.

Es por ello muy conveniente que en todas las cesiones de bienes se eleve a la categoría de condición resolutoria expresa, el cumplimiento exacto por parte del cesionario del fin y destino de los bienes cedidos, con mención del plazo durante el cual haya de cumplirse el fin y mantenerse su destino, advirtiéndose que en caso de incumplimiento bastará acreditarse los hechos mediante acta notarial, la cual, juntamente con la escritura de cesión, pueden motivar la nueva inscripción registral.

De este modo se conjuga perfectamente toda la legislación hipotecaria, sin que los terceros adquirentes puedan llamarse a engaño y la resolución se produciría ex tunc, aplicándose correctamente los artículos 23 de la Ley Hipotecaria y 56, 174 y 175 de su Reglamento.

B) Traspaso de la propiedad de edificios escolares estatales a favor de los Ayuntamientos.

Ya hemos visto cómo el artículo 23 del Decreto-ley de 2 de julio de 1964 atribuye a los Municipios la plena propiedad de los edificios escolares y viviendas para maestros existentes en sus respectivos términos, si bien no se podrán dedicar a fines distintos a la enseñanza sin previa autorización del Ministerio de Educación y Ciencia.

Este precepto nos obliga a plantear la cuestión de cuál sea 
el título en virtud del cual se practicará en el Registro de la Propiedad la debida inscripción de los inmuebles cuya propiedad ha sido transmitida a los Ayuntamientos.

Evidentemente cabe distinguir dos supuestos:

1.- Que los bienes no se hallaren inscritos en dicho Registro, en cuyo caso será procedente el modo de inmatriculación que arbitra el artículo 206 de la Ley Hipotecaria y artículo 303 de su Reglamento.

2. Que los bienes estuvieren inscritos a favor del Estado. En tal evento la Corporación local interesada deberá adoptar un acuerdo en el que, además de exponer los antecedentes del caso, solicite del Ministerio de Hacienda (Patrimonio del Estado) se digne autorizar el otorgamiento de la pertinente escritura pública en la que conste la cesión de aquellos bienes a favor de la respectiva Entidad local.

\section{CONCLUSION}

La tutela de los bienes de las Entidades locales requiere un instrumento jurídico que garantice sus respectivos patrimonios. El Inventario, de acuerdo con la configuración legal vigente, adolece, a nuestro juicio, de una sensible falta de vigor jurídico que, en definitiva, menoscaba su eficacia.

En realidad, la verdadera tutela patrimonial la ejerce el Registro de la Propiedad aun cuando no tengan acceso al mismo los bienes muebles y sea discutible el de los de servicio público.

El Inventario se nos antoja una institución híbrida sin demasiado contenido efectivo, si bien debemos admitir que quien intentara dotarle de una mayor virtualidad tropezaría con grandes dificultades y ello porque sería menester rodearlo de seguridades jurídicas que invadirian los preceptos de la legislación hipotecaria, creando una dualidad de instituciones totalmente innecesaria.

Tanto es así que cuando se ha intentado velar por la integridad de los patrimonios locales y provinciales se ha acudido a la institución del Registro de la Propiedad, encomendando a sus 
titulares las funciones de tutores de aquéllos como así lo previene el artículo 35.4 del Reglamento de Bienes.

Sería absurdo en el mundo del Derecho que coexistieran dos instrumentos de garantía patrimonial (Inventario y Registro de la Propiedad) con idéntica finalidad. Uno de ellos debe ceder frente al otro, y en este caso nos inclinamos, dada su especialización, por ceder la primacía al Registro de la Propiedad, si bien abogando para que deban obligatoriamente inmatricularse en él todos los bienes inmuebles afectos al servicio público, tal como defiende un amplio sector de la doctrina (22).

Paralelamente, debería aclararse o ampliarse el contenido del Inventario (según se ha indicado), reforzando su utilidad como registro administrativo $y$, en consecuencia, favoreciendo la aplicación práctica de las normas sobre Inventario, que no han encontrado todavía el desarrollo deseable.

(22) Véase la nota número 17 de este trabajo. 